\title{
Increased moxifloxacin utilization associated with an unrestricted addition to a drug reimbursement formulary: A population-based analysis
}

\author{
Alissa Jade Wright MD FRCPC ${ }^{1}$, Fawziah Marra PharmD ${ }^{1,2}$, Mei Chong MSc ${ }^{3}$, Catharine Chambers $\mathrm{MSc}^{3}$, \\ William R Bowie MD FRCPC ${ }^{1}$, David M Patrick MD FRCPC $\mathrm{MHSC}^{3,4}$
}

\begin{abstract}
AJ Wright, F Marra, M Chong, C Chambers, WR Bowie, DM Patrick. Increased moxifloxacin utilization associated with an unrestricted addition to a drug reimbursement formulary: A population-based analysis. Can J Infect Dis Med Microbiol 2014;25(1):27-31.
\end{abstract}

OBJECTIVES: To determine whether utilization of moxifloxacin, a broad-spectrum fluoroquinolone antibiotic, has changed since its addition to the British Columbia provincial formulary in 2009 and to determine whether utilization was guideline concordant.

METHODS: BC PharmaNet prescriptions for moxifloxacin from 2001 to 2010 were anonymously linked to associated Medical Services Plan fee-for-service practitioner claims for indication-specific analysis. Prescribing trends for adults $\geq 18$ years of age were described using defined daily dose (DDD) per 1000 person-years. Monthly utilization rates were fit to a linear regression model that controlled for seasonal variation to examine the effect of the formulary addition.

RESULTS: Utilization rose more than sevenfold throughout the study period, from 21.3 DDD per 1000 person-years in 2001 to 163.3 DDD per 1000 person-years in 2010. Although the formulary addition was not associated with an immediate increase in utilization $(7.5 \%$ [95\% CI $-4.4 \%$ to $20.9 \%$ ]; $\mathrm{P}=0.226$ ), it was associated with an overall increase in utilization of $2.1 \%(95 \%$ CI $1.3 \%$ to $3.0 \%$; $\mathrm{P}<0.001)$ for every month after 2009 . Overall, only $29 \%$ of moxifloxacin prescriptions could be linked to a diagnostic code that was considered to be guideline concordant. In more than one-half of moxifloxacin prescriptions, the patient had not used another antibiotic in the previous 90 days. Among moxifloxacin prescriptions in which another antibiotic had been used in the previous 90 days, $41.5 \%$ were prescriptions for an alternative fluoroquinolone.

CONCLUSIONS: The formulary addition was associated with a sustained increase in moxifloxacin utilization over time. Moxifloxacin is often prescribed to patients for indications that are not guideline concordant or to patients who have not previously received first-line antibiotics.

Key Words: Antibiotic stewardship; Drug monitoring; Drug utilization; Population analysis

\author{
L'utilisation accrue de moxifloxacine associée à son \\ ajout non restreint à un formulaire de \\ remboursement de médicaments : une analyse en \\ population
}

OBJECTIFS : Déterminer si l'utilisation de moxifloxacine, un antibiotique de la famille des fluoriquonolones à large spectre, a changé depuis son ajout au formulaire provincial de la Colombie-Britannique en 2009 et établir si cette utilisation concorde avec les lignes directrices.

MÉTHODOLOGIE : Les chercheurs ont lié de manière anonyme les prescriptions de moxifloxacine figurant dans BC PharmaNet de 2001 à 2010 aux réclamations des médecins rémunérés à l'acte auprès du régime d'assurance-maladie connexe en vue d'une analyse propre aux indications. Ils ont décrit les tendances de prescription aux adultes de 18 ans ou plus au moyen de la dose quotidienne déterminée (DQD) sur 1000 années-personne. Les taux d'utilisation mensuels respectaient un modèle de régression linéaire de variation saisonnière afin d'examiner l'effet de l'ajout au formulaire.

RÉSULTATS : L'utilisation a plus que septuplé pendant la période de l'étude, passant de 21,3 DQD sur 1000 années-personnes en 2001 à 163,3 DQD sur 1000 années-personne en 2010. Même si l'ajout au formulaire ne s'associait pas à une augmentation immédiate de l'utilisation (7,5 \% [95 \% IC -4,4\% à 20,9\%]; P=0,226), il s'associait à une augmentation globale d'utilisation de 2,1\% (95\% IC 1,3\% à $3,0 \% ; \mathrm{P}<0,001)$ chaque mois après 2009. Dans l'ensemble, seulement $29 \%$ des prescriptions de moxifloxacine pouvaient être liées à un code diagnostique considéré comme correspondant à des lignes directrices. Dans plus de la moitié des prescriptions de moxifloxacine, le patient n'avait pas utilisé d'autre antibiotique au cours des 90 jours précédents. Parmi les prescriptions de moxifloxacine associées à l'utilisation d'un autre antibiotique au cours de 90 jours précédents, 41,5\% étaient des prescriptions pour une autre fluoroquinolone.

CONCLUSIONS : L'ajout au formulaire s'est associé à une augmentation soutenue de l'utilisation de moxifloxacine au fil du temps. La moxifloxacine est souvent prescrite aux patients pour des indications qui ne correspondent pas aux lignes directrices ou à des patients qui n'ont pas reçu d'antibiotiques de première ligne auparavant.
$\mathrm{M}$ oxifloxacin, a broad-spectrum oral fluoroquinolone, was approved by Health Canada in October 2000 for three outpatient indications: acute bacterial sinusitis (ABS), communityacquired pneumonia (CAP) and acute exacerbations of chronic bronchitis (AECB) (1). It has been available in British Columbia (BC) since then, but patients were initially required to pay for it out of pocket or through extended, employment-based health care plans. The provincial drug coverage program, Pharmacare, only reimburses the cost of prescription drugs that are listed on the provincial formulary and that have been deemed efficacious and cost effective during a comprehensive review. Moxifloxacin was not added to the provincial formulary in BC until January 15, 2009 (2).

Before the formulary change, there were concerns that prescribing restrictions should be placed on moxifloxacin given the potential for inappropriate use of such a broad-spectrum antibiotic. Instead, the BC Ministry of Health chose to implement guidelines in November 2009 for appropriate moxifloxacin utilization, which specify that moxifloxacin should only be prescribed for Health Canada-approved

${ }^{1}$ Department of Medicine, Division of Infectious Disease, University of British Columbia, Vancouver General Hospital; ${ }^{2}$ Faculty of Pharmaceutical Sciences, University of British Columbia; ${ }^{3}$ British Columbia Centre for Disease Control; ${ }^{4}$ chool of Population and Public Health, University of British Columbia, Vancouver, British Columbia

Correspondence: Dr David M Patrick, 655 West 12th Avenue, Vancouver, British Columbia V5Z 4R4. Telephone 604-707-2541,

fax 604-707-2516, e-mail david.patrick@bccdc.ca 
TABLE 1

Coefficients and standard errors for final linear regression model

\begin{tabular}{|c|c|c|c|c|c|}
\hline Term & Coefficient & SE $(\beta)$ & $(\operatorname{Exp}[\beta]-1)^{*} 100 \%$ & $95 \% \mathrm{Cl}$ for $\operatorname{Exp}(\mathrm{B})$ & $\mathbf{P}$ \\
\hline Constant $\left(\beta_{0}\right)$ & 0.2785 & 0.0359 & & & $<0.001$ \\
\hline Time (in months) $\left(\beta_{1}\right)$ & 0.0461 & 0.0017 & 4.7 & $4.4-5.1$ & $<0.001$ \\
\hline $\operatorname{Time}^{2}\left(\beta_{2}\right)$ & -0.0003 & 0.0000 & 0.0 & $0.0-0.0$ & $<0.001$ \\
\hline Cosine term $\left(\beta_{4}\right)$ & 0.1675 & 0.0148 & 18.2 & $14.8-21.8$ & $<0.001$ \\
\hline Indicator for $2009\left(\beta_{5}\right)$ & 0.0721 & 0.0592 & 7.5 & $-4.4-20.9$ & 0.226 \\
\hline Time (in months) since $2009\left(\beta_{6}\right)$ & 0.0212 & 0.0040 & 2.1 & $1.3-3.0$ & $<0.001$ \\
\hline $\mathrm{R}^{2}$ & \multicolumn{5}{|c|}{$R^{2}=0.972$} \\
\hline
\end{tabular}

indications and only as second- or third-line therapy. However, should physicians deviate from this provincial guideline, no penalty system exists.

The objectives of the present study were to determine whether introduction of moxifloxacin to the BC provincial formulary in January 2009 had an immediate impact on outpatient moxifloxacin utilization and to determine whether its introduction was associated with any sustained temporal change in utilization rates compared with the predicted baseline trend. We also sought to determine whether outpatient moxifloxacin utilization was concordant with approved indications and whether its use was limited to second- or third-line therapy as per provincial guidelines. It was hypothesized that adding moxifloxacin to the formulary without restriction would significantly increase the prescription rate and that a substantial proportion of moxifloxacin prescriptions would be discordant with provincial guidelines given the absence of restrictions.

\section{Patients}

\section{METHODS}

$\mathrm{BC}$ is Canada's westernmost province, with an estimated total population of 4.4 million in 2009 (3). Individuals $\geq 18$ years of age were included in the study if they had a prescription for moxifloxacin (Anatomical Therapeutic Chemical code J01MA14) dispensed between January 1, 2001 and December 31, 2010 (4). The analysis was restricted to adults because moxifloxacin is not licensed in Canada for individuals $<18$ years of age.

\section{Study design}

Drug utilization data were obtained from the BC PharmaNet database. PharmaNet is a provincial network that links all outpatient BC pharmacies to a secure central database, creating a complete record of all outpatient prescriptions for each individual. Under-reporting and misclassification with this type of database is minimal (5); however, inpatient prescriptions are not captured in the dataset. The PharmaNet database was anonymously linked using patient and physician identifiers to Medical Service Plan (MSP) practitioner claims with service dates within five days of the prescription dispensing date to derive indication-specific antibiotic prescriptions. The MSP database includes all claims for medically necessary services provided by practitioners remunerated under a fee-for-service payment plan to eligible $\mathrm{BC}$ residents; it contains demographic information regarding physicians and patients, and information regarding physician visits and reimbursement claims. All claims include a diagnostic code defined using the International Classification of Diseases, Ninth Revision (ICD-9) or a small second set of codes unique to $\mathrm{BC}(6,7)$. Service claims that were submitted in the five days before the prescription dispensing date were chosen to represent the medical reason for that prescription, as described previously (8). If more than one physician encounter could be found within the five-day window, the claims with the service date closest to the prescription dispensing date were selected for analysis.

The three approved clinical conditions for moxifloxacin were defined according to the following ICD-9 diagnostic codes: ABS by 'acute sinusitis (461)'; CAP by 'pneumococcal pneumonia (481)', 'other bacterial pneumonia (482)', 'pneumonia due to other specified organism (483)', 'bronchopneumonia, organism unspecified (485)' and 'pneumonia, organism unspecified (486)'; and AECB by 'bronchitis, not specified as acute or chronic (490)', 'chronic bronchitis (491)', 'emphysema (492)' and 'chronic airway obstruction, not elsewhere classified (496)'. The ICD-9 code for emphysema was included for AECB because the provincial guidelines do not differentiate among subtypes of chronic obstructive pulmonary disease (COPD). All patients with COPD in BC meet the criteria for antibiotic treatment for an acute exacerbation, consistent with national guidelines $(9,10)$. AECB was also defined by the complex care diagnostic codes 'asthma and COPD (A491)', 'cerebrovascular disease and COPD (C491)', 'diabetes and COPD (D491)', 'congestive heart failure and COPD (H491)', 'ischemic heart disease and COPD (I491)' and 'chronic kidney disease and COPD (R491)', which increase reimbursement to physicians who care for patients with COPD and an additional chronic health condition (7). Because multiple MSP billings can be submitted for a single physician encounter, linkages to multiple ICD-9 diagnostic codes are theoretically possible. In instances for which a prescription could be linked to more than one diagnostic code, precedence was given to diagnostic codes defined as concordant (ie, ABS, AECB or CAP). In instances for which prescriptions could be linked to more than one concordant diagnostic code, precedence was given to CAP diagnostic codes over AECB codes and AECB codes over ABS codes.

Antibiotic utilization rates were calculated using defined daily doses (DDD) per 1000 people per year. DDD is a standard unit of measurement developed by the WHO to describe the "average maintenance dose of the drug used on its major indication in adults" (4). Total population estimates were generated from the Population Estimates and Projections project, which estimates the number of individuals in BC between census years (3).

Analyses were performed using SAS version 9.3 (SAS Inc, USA) and SPSS version 14.0 (IBM Corporation, USA) for Windows (Microsoft Corporation, USA). To examine the impact of adding moxifloxacin to the provincial formulary in January 2009, a regression model was fit to predict trends in antibiotic utilization rates from 2001 to 2010. The natural log of the monthly rate of utilization was used as the dependent variable to account for the increase in utilization variance over the study period. The parameters of the model were optimized to account for seasonal variations in antibiotic prescribing and long-term trends in moxifloxacin utilization as well as to estimate the impact of adding moxifloxacin to the formulary. The final regression model was described by $\ln (\mathrm{DDD} / 1000$ person-months $)=\beta_{0}+\beta_{1} \mathrm{~T}+$ $\beta_{2} T^{2}+\beta_{3} \sin (2 \pi T / 12)+\beta_{4} \cos (2 \pi T / 12)+\beta_{5} C+\beta_{6} T_{m}$, in which $x T=$ time in months, $\mathrm{C}=$ indicator variable equal to 1 for the year 2009 and 0 for all years before 2009, and $T_{m}=$ time in months since 2009 . Regression coefficients and their standard errors for the final regression model are presented in Table 1 . Sine and cosine terms were included in the model to adjust for seasonal trends.

The data used in the present study were not from a random sample but included all ambulatory prescriptions dispensed in BC. Therefore, 


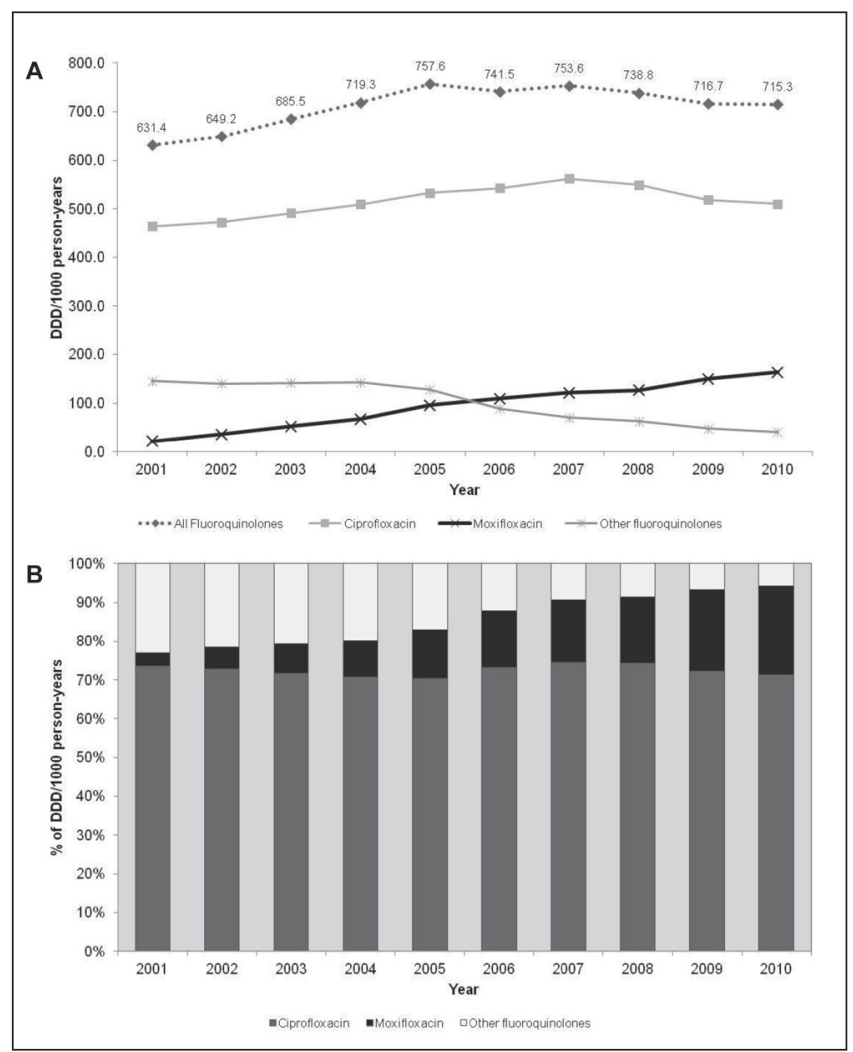

Figure 1) A Utilization rate in defined daily doses (DDD) per 1000 personyears of all fluoroquinolones and major Anatomical Therapeutic Chemical classes (ciprofloxacin, moxifloxacin and other fluoroquinolones) among adults $\geq 18$ years old in British Columbia according to year, 2001 to 2010. B Utilization rate of ciprofloxacin, moxifloxacin and other fluoroquinolones as a proportion of overall fluoroquinolone use among adults $\geq 18$ years of age in British Columbia according to year, 2001 to 2010

statistical measures reflecting sampling variability (eg, $\mathrm{P}$ values and CIs) are not reported for antibiotic utilization rates and proportions. $\chi^{2}$ tests were used to assess trends in aggregate rates and proportions over time. The present study was approved by the Research Ethics Board at the University of British Columbia (Vancouver, British Columbia) (H09-00650).

\section{RESULTS}

There were a total of 395,150 prescriptions for moxifloxacin dispensed to adults $\geq 18$ years of age during the 10-year study period (2001 to 2010); these prescription records represented 244,082 unique patients and 8566 unique prescribers. Overall, 324,706 (82.2\%) moxifloxacin prescriptions could be linked to a physician reimbursement claim to derive diagnostic information. The proportion of moxifloxacin prescriptions that could be linked to a physician claim significantly declined during the study period from $84.9 \%$ in 2001 to $80.3 \%$ in 2010 $\left(\chi^{2}=861.9\right.$; degrees of freedom $\left.[\mathrm{df}]=9 ; \mathrm{P}<0.01\right)$. Because multiple physician claims can be submitted for a single physician encounter, a prescription record could be linked to multiple diagnostic codes. Among moxifloxacin prescriptions that could be linked to a physician claim, the vast majority $(98.8 \%)$ were linked to a single diagnostic code. The median number of linked diagnoses per prescription was one, while the maximum was five.

Among adults $\geq 18$ years of age, the rate of moxifloxacin use increased during the study period from 21.3 DDD per 1000 person-years in 2001 to 163.3 DDD per 1000 person-years in 2010 (Figure 1A). This increase in moxifloxacin utilization was observed against a background increasing trend in overall fluoroquinolone use from 2001 to 2005, after which the trend stabilized and began to decrease slightly until

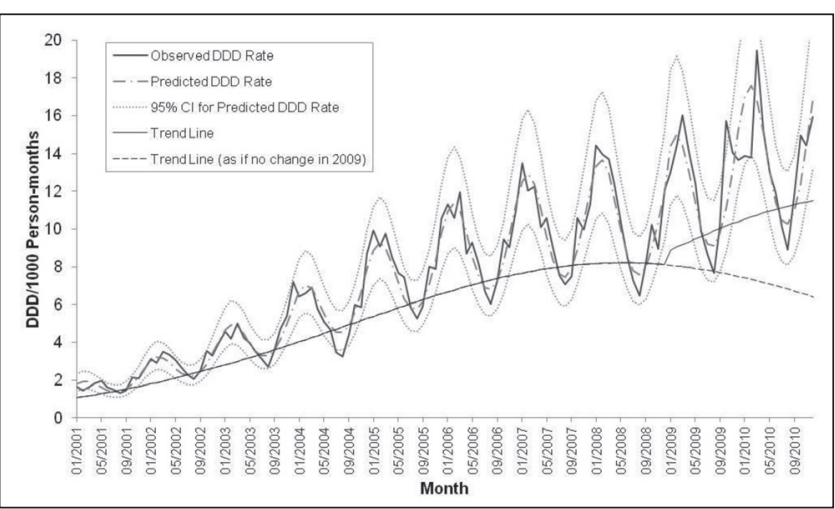

Figure 2) Observed defined daily dose (DDD) per 1000 person-months compared with the predicted DDD per 1000 person-months generated by the linear regression model with 95\% CIs created using time, seasonality and 2009 as independent predictive values for adults $\geq 18$ years of age in British Columbia according to month, January 2001 to December 2010. The trend line highlights the change in prescribing in 2009 associated with the unrestricted addition of moxifloxacin to the provincial drug formulary

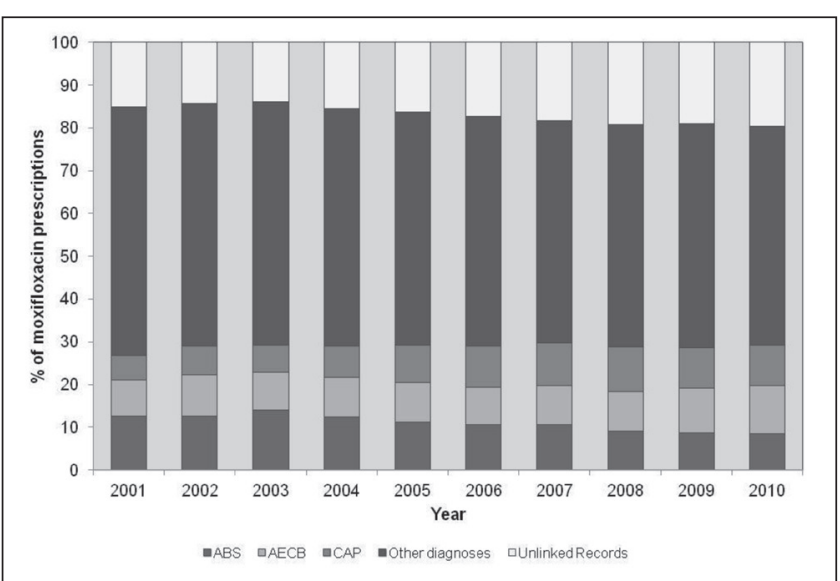

Figure 3) Proportion of moxifloxacin prescriptions that could be linked to International Classification of Diseases, Ninth Revision diagnostic codes for acute bacterial sinusitis (ABS), acute exacerbations of chronic bronchitis (AECB), community-acquired pneumonia (CAP) and other diagnoses among adults $\geq 18$ years of age in British Columbia according to year, 2001 to 2010

2010. The rate of moxifloxacin prescriptions as a proportion of all fluoroquinolone use increased during the study period from $3.4 \%$ in 2001 to $22.8 \%$ in 2010 (Figure 1B).

The immediate impact of the addition of moxifloxacin to the provincial formulary in 2009 was associated with a nonsignificant increase in utilization of $7.5 \%(95 \% \mathrm{CI}-4.4 \%$ to $20.9 \%[\mathrm{P}=0.226])$ above that predicted by the trend of the preceding eight years (Table 1 and Figure 2). However, the rate of change (ie, slope) in moxifloxacin utilization remained above the expected trend post-formulary change; for every month additional after 2009, there was a significant increase in utilization of $2.1 \%$ (95\% CI $1.3 \%$ to $3.0 \%[\mathrm{P}<0.01])$ over the predicted trend. The model accounted for $97.2 \%$ of the variability in prescribing rates $\left(\mathrm{F}=665.9 ; \mathrm{df}=6,113 ; \mathrm{P}<0.001 ; \mathrm{R}^{2}=0.972\right)$. Time and seasonal variation (denoted by both sine and cosine terms) were also significant factors associated with changes in prescribing $(\mathrm{P}<0.001)$.

Of the 395,195 moxifloxacin prescriptions dispensed during the study period, 114,630 (29.0\%) were linked to an appropriate diagnosis: 40,189 (10.1\%) were linked to diagnostic codes for ABS, 38,456 (9.7\%) for AECB and 35,985 (9.1\%) for CAP (Figure 3). The proportion of moxifloxacin prescriptions that could be attributed to one of the 


\section{TABLE 2 \\ Distribution of International Classification of Diseases, Ninth Revision (ICD-9) diagnostic codes linked to moxifloxacin prescriptions, 2001 to $2010^{*}$}

\begin{tabular}{|c|c|}
\hline Diagnosis (ICD-9 code) & $\begin{array}{l}\text { Within all moxifloxacin } \\
\text { prescriptions, \% }\end{array}$ \\
\hline Acute bronchitis and bronchiolitis (466) & 11.2 \\
\hline Acute sinusitis $(461)^{\dagger}$ & 10.1 \\
\hline $\begin{array}{l}\text { Symptoms involving respiratory system and other } \\
\text { chest symptoms (786) }\end{array}$ & 8.6 \\
\hline Pneumonia, organism unspecified $(486)^{\dagger}$ & 6.4 \\
\hline Bronchitis, not specified as acute or chronic $(490)^{\dagger}$ & 5.5 \\
\hline $\begin{array}{l}\text { Acute upper respiratory infections of multiple or } \\
\text { unspecified site (465) }\end{array}$ & 2.7 \\
\hline Asthma (493) & 2.3 \\
\hline $\begin{array}{l}\text { Chronic airways obstruction, not elsewhere } \\
\text { classified (496) }\end{array}$ & 2.1 \\
\hline General symptoms $(780)$ & 1.9 \\
\hline Symptoms involving head and neck (784) & 1.7 \\
\hline Chronic pharyngitis and nasopharyngitis (472) & 1.6 \\
\hline Chronic sinusitis (473) & 1.5 \\
\hline Other bacterial pneumonia $(482)^{\dagger}$ & 1.4 \\
\hline Chronic bronchitis $(491)^{\dagger}$ & 1.4 \\
\hline Acute nasopharyngitis (common cold) (460) & 1.4 \\
\hline Acute pharyngitis (462) & 1.1 \\
\hline Essential hypertension (401) & 0.9 \\
\hline Bronchopneumonia, organisms unspecified $(485)^{\dagger}$ & 0.8 \\
\hline Viral pneumonia (480) & 0.8 \\
\hline Diabetes mellitus $(250)$ & 0.7 \\
\hline Symptoms involving cardiovascular system (785) & 0.6 \\
\hline $\begin{array}{l}\text { Symptoms involving nervous and musculoskeletal } \\
\text { systems (781) }\end{array}$ & 0.6 \\
\hline $\begin{array}{l}\text { Pneumonia in infectious diseases classified else- } \\
\text { where (eg, measles, cytomegalic inclusion } \\
\text { disease, ornithosis, whooping cough) (484) }\end{array}$ & 0.6 \\
\hline Heart failure (428) & 0.6 \\
\hline Suppurative and unspecified otitis media (382) & 0.5 \\
\hline Emphysema $(492)^{\dagger}$ & 0.5 \\
\hline Other diagnoses & 14.9 \\
\hline Unlinked records & 17.8 \\
\hline
\end{tabular}

${ }^{*}$ Restricted to prescription records that could be linked to a single ICD-9 diagnostic code; an additional $3752(<1 \%)$ prescription records could be linked to one or more diagnostic codes and are not captured here; ${ }^{\prime} I C D-9$ diagnostic codes defined as being guideline concordant (ie, included in definition of acute bacterial sinusitis, acute exacerbations of chronic bronchitis and communityacquired pneumonia)

approved indications did not change substantially throughout the study; however, the proportion of unlinked records significantly increased $\left(\chi^{2}=3066.3 ; \quad d f=36 ; \quad P<0.001\right)$. Of the remaining 210,071 linked prescriptions classified as 'other' diagnoses, diseases of the respiratory system comprised the majority of diagnostic codes (Table 2). Other frequently linked diagnostic codes included those for general signs and symptoms and those for common chronic diseases (eg, hypertension, diabetes, heart failure) (Table 2). General practitioners prescribed the majority $(76.5 \%)$ of moxifloxacin prescriptions during the study period, with the remainder being prescribed by a specialist $(5.6 \%)$ or were unable to be linked to prescriber characteristics $(17.8 \%)$.

In $211,423(53.5 \%)$ prescriptions, moxifloxacin was prescribed when patients had not used any other antibiotic in the preceding 90 days. According to diagnostic group, $57.4 \%$ of prescriptions that could be linked to an ABS diagnosis did not have another antibiotic prescribed in the previous 90 days, 53.4\% for AECB, 52.6\% for CAP,
$54.0 \%$ for other diagnoses and $50.3 \%$ for unlinked records. Among moxifloxacin prescriptions in which one or more antibiotics were given in the previous 90 days $(\mathrm{n}=183,727), 76,280(41.5 \%)$ were prescriptions for another fluoroquinolone, including 56,054 (30.5\%) instances in which the previous prescription was another prescription for moxifloxacin.

\section{DISCUSSION}

Our study found that although moxifloxacin use in $\mathrm{BC}$ has been rising since its approval by Health Canada in 2000, its addition to the provincial formulary in 2009 did not have a significant immediate impact on utilization rates above that predicted by trend. The addition of moxifloxacin was, however, associated with a sustained increase in utilization rates of $2 \%$ (95\% CI $1 \%$ to $3 \%$ ) per month for each additional month post-formulary change in 2009 above that predicted by trend.

Fewer than one-third of moxifloxacin prescriptions could be linked to diagnostic codes that would be considered to be concordant with provincial guidelines. According to diagnostic group, $10 \%$ of prescriptions could be linked to diagnostic codes for ABS, 10\% for AECB and $9 \%$ for CAP. The remaining prescriptions were either linked to diagnostic codes considered to be discordant with approved indications $(53 \%)$ or were unable to be linked (18\%). Diagnostic codes within the guideline-discordant group were largely comprised of other diseases of the respiratory tract, such as acute viral infections, in which moxifloxacin, or any antibiotic, would not be indicated. A number of prescriptions were linked to diagnostic codes classified as general signs and symptoms, or were unable to be linked to physician claims. We were not able to determine whether moxifloxacin was prescribed appropriately in these circumstances; consequently, the proportion of prescriptions considered to be guideline concordant reported in the present study is likely an underestimate.

In slightly more than one-half of prescriptions, moxifloxacin was used as first-line therapy, despite provincial guidelines that recommend it only as a second- or third-line drug. Moreover, in the population of patients who have been on antibiotics, more than $40 \%$ of the time moxifloxacin was prescribed when a fluoroquinolone had already been given in the preceding 90 days. In most of these instances, the patient had already received one or more moxifloxacin prescriptions in the previous 90 days. Utilization of the same antibiotic class in this time period is a known risk factor for drug resistance $(9,10)$.

Examination of the trends in moxifloxacin utilization over time within the context of overall fluoroquinolone use suggests that the increase in moxifloxacin utilization may be partially accounted for by substitution of moxifloxacin for other traditionally prescribed respiratory fluoroquinolones such as levofloxacin. Of concern, the increase in moxifloxacin utilization, if sustained, may serve to reverse the stabilizing, if not decreasing, trend in overall fluoroquinolone use observed at the population level in recent years. Since 2006, moxifloxacin has become the predominant fluoroquinolone prescribed for respiratory conditions in BC.

Our results show that unrestricted drug formulary changes can impact antibiotic utilization at a population level. We observed an increase in moxifloxacin utilization following its addition to the provincial formulary in 2009, despite the provision of guidelines to restrict its use to second- or third-line therapy for approved indications. This is likely because there were no consequences imposed for deviating from guideline-recommended care. Drug formularies are one of the main targets of inpatient antibiotic stewardship programs within hospital settings because they can provide "immediate, significant reductions in antimicrobial use" (4). Formulary restriction - through preapproval requirements or prescriber-specific restrictions - could also be an effective outpatient antibiotic stewardship measure in community settings that have outpatient state-wide, provincial or national formularies. Formulary restriction and/or other antibiotic stewardship efforts should be considered during the decision-making process to list (or delist) an antibiotic from a formulary. 
The present study also highlights the potential advisory role that existing antibiotic stewardship programs - such as the "Do Bugs Need Drugs?" program, which was implemented in 2005 in BC to decrease inappropriate community antibiotic use - could play in formulary decisions. Community-based antimicrobial stewardship programs aimed at reducing moxifloxacin utilization now in BC should target unnecessary prescriptions for noninfectious or viral-mediated respiratory conditions such as asthma and nasopharyngitis, while highlighting first- and second-line antibiotic choices for ABS, AECB and CAP. They should also concentrate on improving antibiotic prescribing practices, such as changing drug class when repeated antibiotic exposure is necessary. Any message from these programs needs to be delivered province-wide to all general practitioners to be effective.

There were limitations to the present study because it was retrospective and observational in design. It was performed using the MSP database, which is designed to reimburse physicians, not study prescribing practices. Consequently, $18 \%$ of moxifloxacin prescriptions were unable to be linked to a physician claim. The MSP data are restricted to reimbursement claims from physicians remunerated under a fee-for-service plan; as such, visits to physicians receiving payment under alternative payment plans are not captured in MSP. Linkage failures may also have resulted from incomplete or inaccurate data in the physician identifier conversion files required for identifying prescribers in the PharmaNet data. This latter issue is in the process of being rectified for future data collection. Other linkage failures occur because patients are receiving moxifloxacin on discharge from hospital or via telephone call to the pharmacy (no fee-for-service physician visit) or are filling a prescription from a physician visit that occurred more than five days previously (eg, a refill). This reduced the sensitivity of our analyses because we could only include $82 \%$ of all moxifloxacin prescriptions in indication-specific analyses; consequently, estimates of guideline concordance may be underestimated.

A second limitation was that the definitions for infections had to be obtained from existing ICD-9 codes, which may over- or underestimate disease counts. For example, the code chosen for ABS was 'acute sinusitis'. This does not differentiate between acute bacterial sinusitis, which requires an antibiotic, and acute viral sinusitis, which does not (11). There are also several nonspecific ICD-9 codes related to the respiratory tract (eg, 'symptoms involving the respiratory tract and other chest symptoms') that may have contained a small proportion of patients with either CAP or AECB. This is an inherent limitation of using administrative data to inform evaluation research. However, over- or underestimation cannot account for the large number of indications for which moxifloxacin was prescribed that are not subject to this uncertainty and for which moxifloxacin is not recommended (eg, asthma).

\section{CONCLUSIONS}

Moxifloxacin use in $\mathrm{BC}$ has steadily increased since its introduction to the Canadian market; its unrestricted addition to the provincial formulary was associated with an increase of $2 \%$ per month in utilization above the expected trend. Although most of this utilization was for respiratory tract conditions, it was discordant with provincial guidelines, which only recommend moxifloxacin as a second- or third-line agent for the treatment of selected bacterial infections of the respiratory tract. Physicians are prescribing moxifloxacin as either a first-line agent or to patients who have already been given a fluoroquinolone, including moxifloxacin. These findings should be used to inform future formulary evaluations.

ACKNOWLEDGEMENTS: The authors acknowledge the BC Centre for Disease Control's Do Bugs Need Drugs Program (BCCDC DBND), which is supported by the BC Ministry of Health Pharmaceutical Services Branch.

FUNDING: Funding for the Do Bugs Need Drugs Program at British Columbia's Centre for Disease Control is provided by the BC Ministry of Health Pharmaceutical Services Branch. The authors of this work have not received any specific funding for completion of this work.

DISCLOSURES: AJW, FM, MC, CC, WB and DMP have no conflicts of interest to declare.

\section{REFERENCES}

1. Bayer Inc. Product Monograph. PrAvelox®. <www.hc-sc.gc.ca/dhpmps/prodpharma/databasdon/index-eng.php $>$ (Accessed June 19, 2013).

2. Pharmaceutical Services Division, BC Ministry of Health. BC PharmaCare Newsletter. January 15, 2009. Edition 09-001. <www. health.gov.bc.ca/pharmacare/newsletter/> (Accessed June 19, 2013).

3. BC Stats. Population Estimates. <www.bcstats.gov.bc.ca/ StatisticsBySubject/Demography/PopulationEstimates.aspx > (Accessed June 19, 2013).

4. World Health Organization. Introduction to Drug Utilization Research. Geneva: World Health Organization, WHO International Working Group for Drug Statistics Methodology, WHO Collaborating Centre for Drug Statistics Methodology, WHO Collaborating Centre for Drug Utilization Research and Clinical Pharmacological Services, 2009.

5. Levy AR, O'Brien BJ, Sellors C, Grootendorst P, Willison D. Coding accuracy of administrative drug claims in the Ontario Drug Benefit database. Can J Clin Pharmacol 2003;10:67-71.

6. American Medical Association. International Classification of Diseases, 9th Revision, Clinical Modification (ICD-9-CM). Chicago: American Medical Association, 1997.

7. BC Ministry of Health. Frequently Asked Questions - Full Service Family Practice Incentive Program. <www.health.gov.bc.ca/msp/ legislation/bcmaagree_faqs_fsfp.html> (Accessed June 19, 2013).

8. Marra F, Patrick DM, Chong M, Bowie WR. Antibiotic use among children in British Columbia, Canada. J Antimicrob Chemother 2006;58:830-9.

9. Dellit TH, Owens RC, McGowan JE Jr, et al. Infectious Diseases Society of America and the Society for Healthcare Epidemiology of America guidelines for developing an institutional program to enhance antimicrobial stewardship. Clin Infect Dis 2007;44:159-77.

10. Pedersen G, Schonheyder HC, Steffensen FH, Sorensen HT. Risk of resistance related to antibiotic use before admission in patients with community-acquired bacteraemia. J Antimicrob Chemother 1999;43:119-26.

11. Gwaltney JM Jr. Acute community-acquired sinusitis. Clin Infect Dis 1996;23:1209-23. 


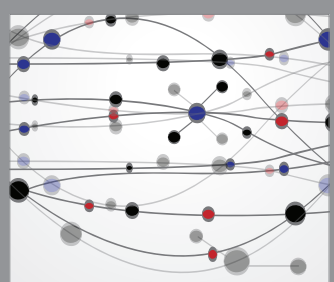

The Scientific World Journal
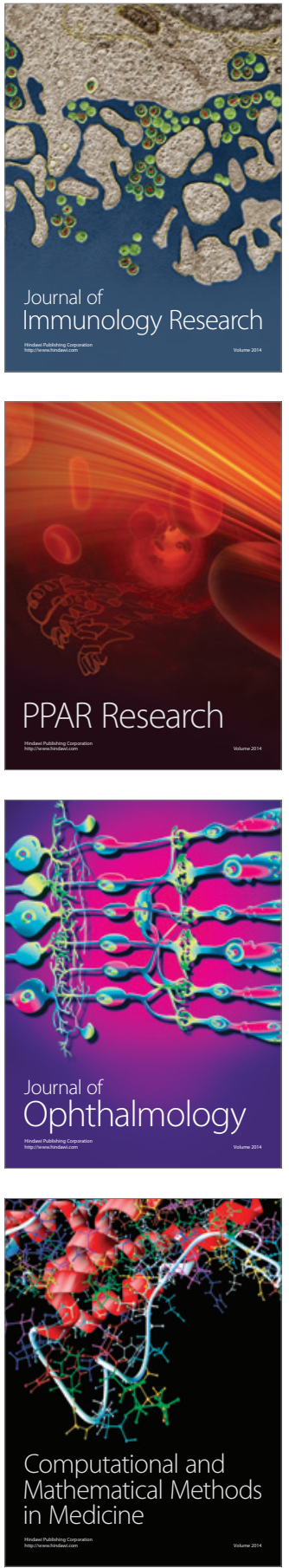

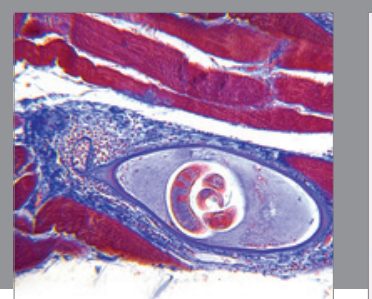

Gastroenterology Research and Practice

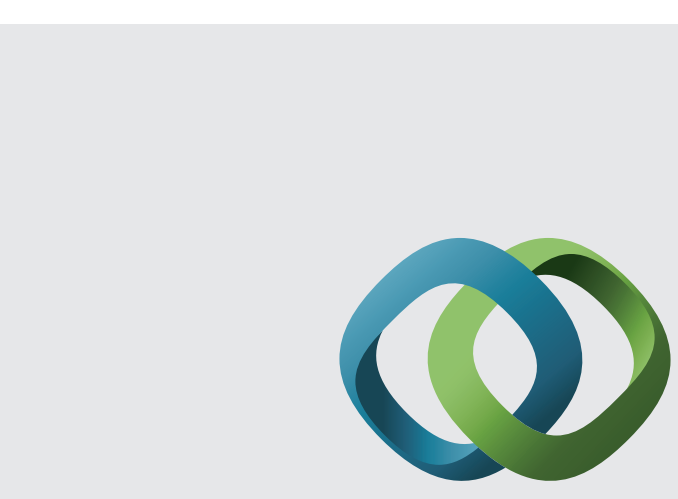

\section{Hindawi}

Submit your manuscripts at

http://www.hindawi.com
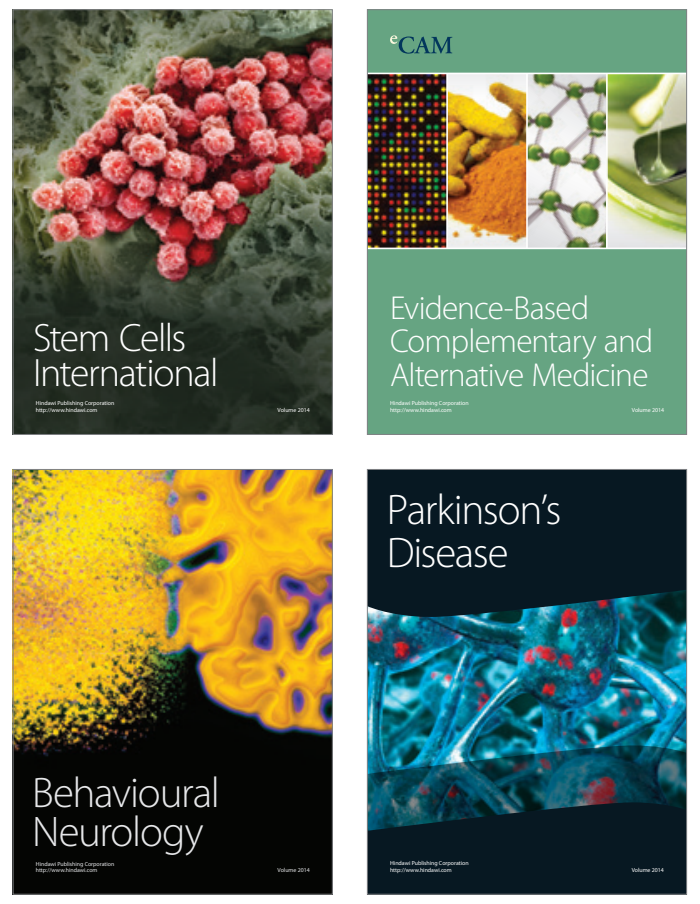
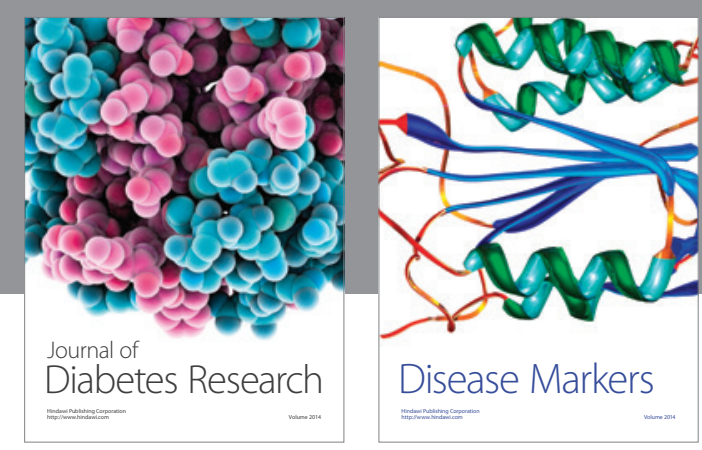

Disease Markers
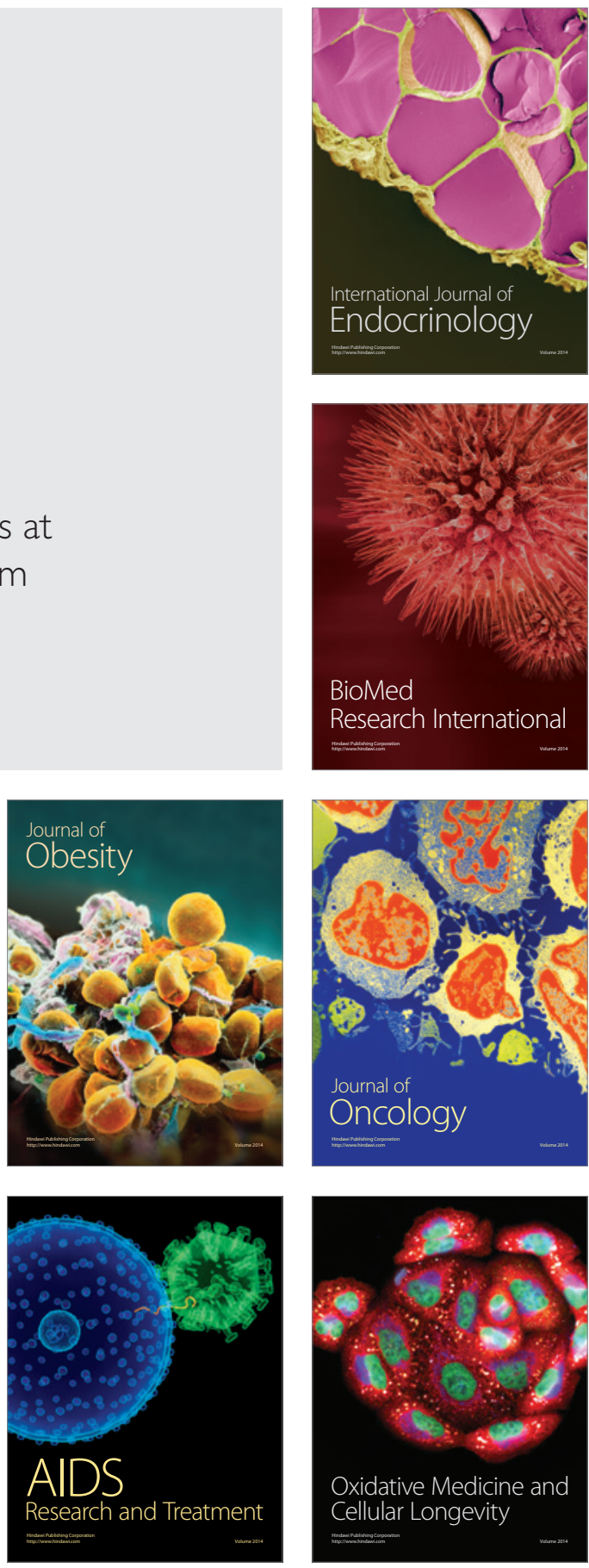